Chirurgia (2019) 114: 809-823

No. 6, November-December

Copyright $@$ Celsius

http://dx.doi.org/10.21614/chirurgia.114.6.809

\title{
Re-sleeve Gastrectomy - An Efficient Revisional Bariatric Procedure - 3 Years Results
}

\author{
Simona Filip ${ }^{1}$, Ionut Hutopila ${ }^{1,2}$, Catalin Copaescu ${ }^{1,3}$ \\ 'Ponderas Academic Hospital Bucharest, Romania \\ 'University of Medicine and Pharmacy "Titu Maiorescu", Bucharest, Romania \\ 3"Grigore T Popa" University of Medicine and Pharmacy, Iasi, Romania
}

Corresponding author: Catalin Copaescu, MD PhD Associated Professor of Surgery Ponderas Academic Hospital Nicolae Caramfil Street, no. 85 A district 1, Bucharest, Romania

E-mail: catalin.copaescu@ponderas-ah.ro

Abbreviations:

LSG - laparoscopic gastric sleeve; BPD-DS - biliopancreatic diversion with duodenal switch;

GBP - gastric bypass;

OAGB - one anastomosis gastric bypass; Duodenal Switch (DS)

SADI - single anastomosis duodeno-lleal bypass;

EGD - esophago-gastro-duodenoscopy; GERD - gastro-esophageal reflux; $\mathrm{HH}$ - hiatal hernia;

HHR - hiatal hernia repair.
Received: 05.11.2019 Accepted: 12.12.2019

\section{Rezumat}

Gastrectomia longitudinală iterativă (Re-sleeve) - o optiune eficientă pentru chirurgia bariatrică revizională - rezultate la 3 ani

Introducere: Gastrectomia longitudinala laparoscopică este o procedură bariatrică larg aplicată cu rezultate bune privind scăderea ponderală şi remisia comorbiditătilor. Pentru pacienții cu recâştig ponderal şi lărgirea tubului gastric, gastrectomia longitudinală iterativă poate fi opțiunea revizională.

Scop: Studiul îşi propune evaluarea rezultatelor gastrectomiei longitudinale ca procedură revizională după gastrectomia longitudinală inițială într-un centru de excelență în chirurgie bariatrică. Metodă: Studiul a presupus o evaluare retrospectivă a bazei de date instituționale menținută prospectiv, identificând 27 de pacienti operati în clinica noastră cu gastrectomie longitudinală laparoscopică (re-sleeve) după gastrectomie longitudinală (gastric sleeve) inițială, în perioada ianuarie 2013 - decembrie 2016. Pacientii au fost urmăriți în conformitate cu programul nostru bariatric standardizat, iar eficienta rezectiei iterative, privind scăderea ponderală şi remisia comorbidităților, au fost evaluate la 6 luni, 1 an şi 3 ani postoperator.

Rezultate: Gastrectomia longitudinală iterativă a fost realizată pe cale laparoscopică în toate cazurile, iar 24 de pacienți (89\%) au avut procedee chirurgicale asociate, la toți aceştia a fost tratată hernia hiatală. Nu au existat complicatiii intra- sau postoperatorii cu exceptia unui caz de stenoză a tubului gastric. Indicele de masă corporală, BMI, înainte de re-sleeve a fost în medie $35,69 \mathrm{~kg} / \mathrm{m}^{2}$ (limite 28,58-52). Urmărirea la 6 luni după re-sleeve a arătat BMI 
în medie $28,39 \pm 5,32 \mathrm{~kg} / \mathrm{m}^{2}$ cu pierderea excesului ponderal EWL 83,88\%, la 1 an BMI în medie $27,23 \pm 5,23 \mathrm{~kg} / \mathrm{m}^{2}$ cu EWL 94,45\% şi la 3 ani BMI in medie 27,65 $\pm 5,13 \mathrm{~kg} / \mathrm{m}^{2}$ cu EWL 85,41\%. Diferențe semnificative statistic $(\mathrm{p}<0,01)$ au fost găsite între BMI înainte de re-sleeve şi BMI la toate momentele evaluate 6 luni, 1 an şi 3 ani după re-sleeve. Toți cei 6 pacienți $(22 \%)$ cu comorbidități înainte de re-sleeve au avut remisia acestor patologii la 1 an postoperator, un singur pacient a prezentat recurența comorbidităților la 3 ani postoperator.

Concluzii: Gastrectomia longitudinala iterative este o opțiune revizională eficienta pentru re-câştig ponderal după gastrectomia longitudinală având, pe termen mediu, un rezultat bun, cu scădere ponderală eficientă si remisia comorbidităților.

Cuvinte cheie: chirurgie bariatrică, chirurgie revizională, re-sleeve, recâştig ponderal

\section{Abstract}

Background: Laparoscopic gastric sleeve is a well-known bariatric procedure with good results on weight loss and remission of comorbidities. For patients with weight regain and a large sleeved stomach, the laparoscopic re-sleeve (re-LSG) can be considered a revisional option.

Aim: The objective of this study is to evaluate the results of laparoscopic re-sleeve as revisional procedure in patients with weight regain after gastric sleeve, in a Center of Excellence in Bariatric Surgery (BS-CoE).

Method: A retrospective evaluation of a prospectively maintained database identified 27 patients who underwent laparoscopic gastric re-sleeve after gastric sleeve from January 2013 - December 2016 in our BS-CoE. Patients were monitored in conformity with our standard bariatric program and the efficiency of re-sleeve in terms of weight loss and comorbidities outcome was evaluated at 6 months, 1 year and 3 years postoperative.

Results: Re-sleeve gastrectomy was performed by laparoscopic approach in all cases and 24 (89\%) patients had concurrent surgical procedures, all of them hiatal hernia repair. No intra or postoperative complications were found except one case of gastric tube stenosis. Mean BMI before resleeve was $35.69 \mathrm{~kg} / \mathrm{m}^{2}$ (range 28,58-52) and follow-up results at 6 months after re-sleeve revealed mean BMI was $28.39 \pm 5.32 \mathrm{~kg} / \mathrm{m}^{2}$ with EWL $83.88 \%$, at 1 year mean BMI $27.23 \pm 5.23 \mathrm{~kg} / \mathrm{m}^{2}$ with EWL $94.45 \%$ and at 3 years BMI $27.65 \pm 5.13 \mathrm{~kg} / \mathrm{m}^{2}$ with EWL $85.41 \%$. There are statistically significant differences $(\mathrm{p}<0.01)$, between BMI before re-sleeve and BMI for all other moments of measurement 6 months, 1 year and 3 years after re-sleeve. All the 6 patients $(22 \%)$ with comorbidities before re-sleeve had remission of their diseases at ne year postoperative, but 1 patient had recurrence of hypertension at 3 years postoperative.

Conclusion: Laparoscopic redo sleeve is an efficient revisional surgery option for weight regain after primary gastric sleeve with effective weight loss and improvement of comorbidities in a medium term follow-up.

Key words: bariatric surgery, revisional surgery, re-sleeve gastrectomy, weight regain

\section{Introduction}

Laparoscopic gastric sleeve (LSG) has proven its' efficiency for weight loss and improvement of comorbidities, while associating low post- operative morbidity. Therefore, it has become a very popular bariatric procedure.

However, a poor control of the weight loss or even weight regain may occur after gastric sleeve. The patients can experience a progres- 
sive weight regain after an inadequate weight loss after LSG (defined as loss of less than 50\% of excess weight) or after reaching the optimal weight loss.(1)

Moreover, on mid- and long term, weight regain has been reported after all bariatric operations, including LSG. Therefore, revisional bariatric surgery comprises $5 \%-15 \%$ of total cases of bariatric surgery (1-3). The rate of revisional surgery is $20 \%-60 \%$ after LAGB (4-8), 9\%-17\% after RYGB $(9,10)$, and 9\%-11\% after SG $(11,12)$.

As it was initially proposed, LSG may be the first stage procedure for super-obese patients, helping patients to lose weight, ameliorate their comorbidities and reducing the risk of the second stage surgery represented by laparoscopic biliopancreatic diversion with duodenal switch (BPD-DS), or gastric bypass (GBP) $(13,14)$. At that stage, the sleeve construction may be revised, too.

Several options to revise a gastric sleeve for weight regain are considered: iterative resection, known as re-sleeve (Re-SLG), banding the sleeve (B-SG), Roux en Y gastric bypass RYGB/ one anastomosis gastric bypass (OAGB), duodenal switch (DS), single anastomosis duodeno-ileal bypass (SADI) (3,6,13, 15-17). The decision will be taken after performing an extended evaluation of the patient's alimentary behavior and medical status, and of the anatomy of LSG.

Re-LSG can be the appropriate surgical option as a revisional procedure for patients with dilated gastric tube, entirely or only a part like a dilated antrum or a large gastric fundus, having in common a too large capacity of the stomach (9-11).

The objective of this study is to evaluate the efficiency of laparoscopic re-sleeve as a revisional procedure for patients presenting weight regain after LSG, in a Bariatric Surgery Center of Excellence (BS-CoE).

\section{Method}

The prospectively maintained institutional database, recording all the patient who have received bariatric surgery in our Metabolic and Bariatric Surgery Center of Excellence between January 2013 and December 2016 was analyzed. All the patients who underwent re-sleeve (Re-LSG) as a revisional bariatric procedure for weight regain, in the mentioned time interval, were subjected to a retrospective evaluation.

The patients initially considered for $\mathrm{Re}^{-}$ LSG and, receiving another treatment or surgical procedure for weight regain, were excluded from the study. The patients who, for any reason, were lost for follow-up for at least 3 years postoperative were not analyzed.

The LSG patients who needed any reoperation to correct a postoperative early or late complication such as obstruction, GERD, bleeding or sepsis were excluded from the study.

The preoperative evaluation data consisting of age, gender, BMI before the primary gastric sleeve, and the postoperative weight, BMI and comorbidities' evolution at 6 months, 1 year and 3 years after Re-LSG were analyzed. The weight regains before $\mathrm{Re}^{-}$ LSG, the time interval between initial sleeve and re-sleeve were calculated. The technical aspects and the outcomes the Re-LSG procedure were explored in detail.

An informed consent was signed from all the patients. The institutional IRB approved the introduce the Re-SLG operation and run the present study.

\section{Decision Making Strategy}

The indication for laparoscopic revisional surgery was weight regain, consecutive an insufficient weight loss after the initial sleeve or weight regain after an optimal weight loss after LSG.

The metabolic multidisciplinary team included surgeon, nutritionist, psychologist, endocrinologist, cardiologist and anesthetist has evaluated each patient. An extended preoperative evaluation consisting of the detailed history of dietary habits, weight progress after initial sleeve and the evolution of comorbidities was done. The evaluation of the anatomy of the gastric tube was performed in all 
patients and has included upper digestive endoscopy, upper GI barium swallow study and CT scan with $3 \mathrm{D}$ reconstruction. A 24 $\mathrm{pH}$-metry monitoring study was performed in all the candidates to revisional surgery.

Upper gastrointestinal barium swallow study can appreciate the dilation of the gastric tube, as a global dilation (Fig. 1) or of a part of the stomach, such as, the undissected gastric antrum (Fig. 2 and Fig. 3) or gastric fundus, by measuring the volume of the gastric tube. The investigation may also provide information about gastroesophageal reflux and hiatal hernia or the transhiatal migration of the gastric tube, if the metallic marker of the proximal stapled line is present above the diaphragm. The gastric emptying is also be evaluated.

Esophago-gastro-duodenoscopy (EGD), was indicated in all cases under iv anesthesia, searching for information about the gastroesophageal reflux (GERD), identifying esophagitis and its' severity, by the Los Angeles grade of esophagitis (18), looking for transhiatal migration of the gastric tube and hiatal

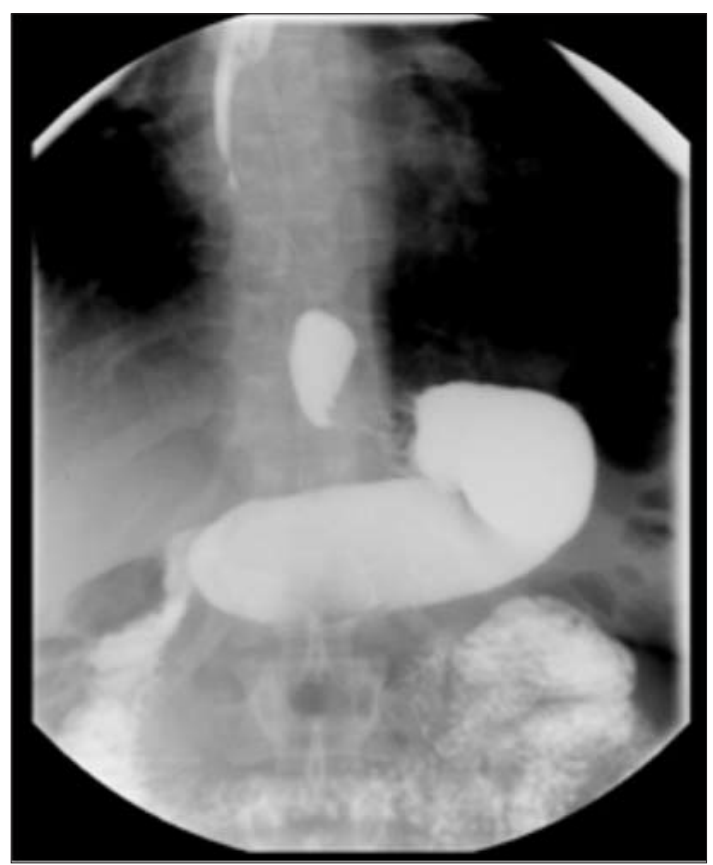

Figure 1. Barium swallow Upper Gl Study - globally dilated gastric tube after initial gastric sleeve; hiatal hernia is revealed in Trendelenburg position

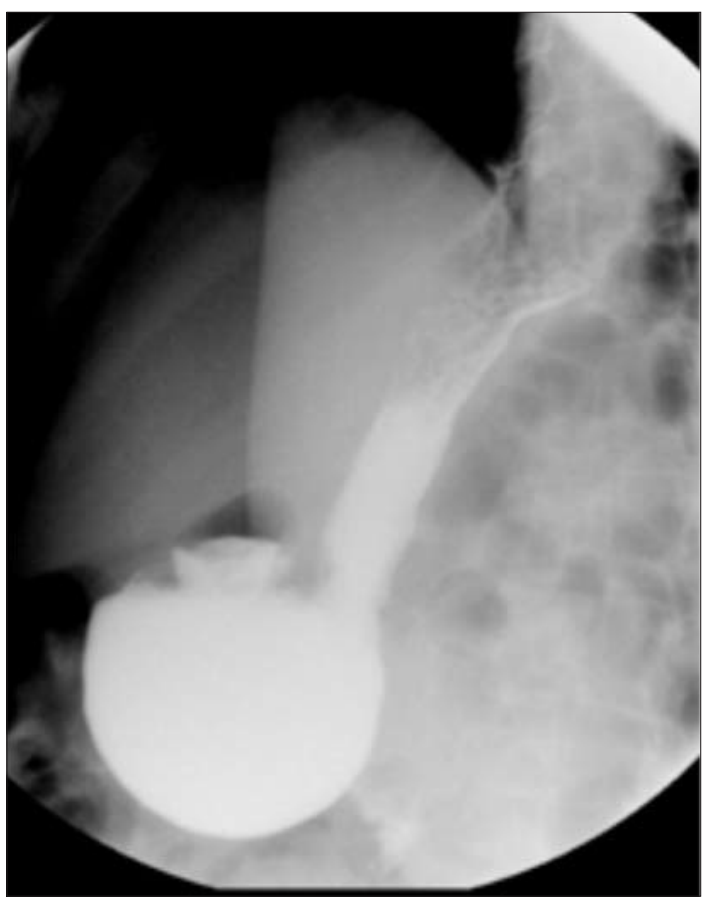

Figure 2. Barium swallow Upper GI Study - patient with a dilated an important dilation of the gastric antrum

hernia. EGD is offering information relative to the gastric tube volume, considering the

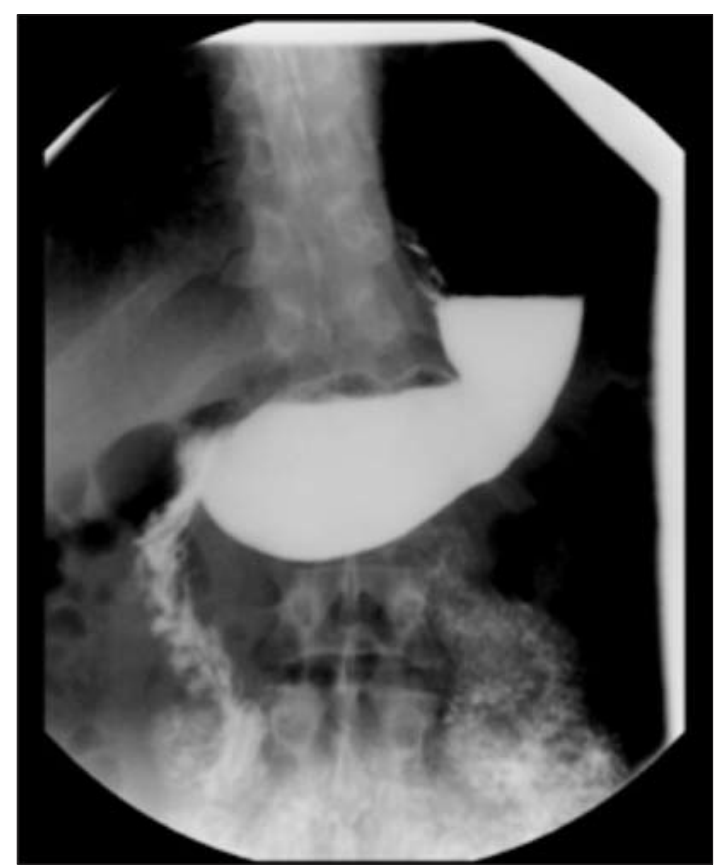

Figure 3. Barium swallowUpper GI Study - dilated gastric tube and of the undissected gastric antrum 
possibility of "U-turn" exploration a sign of an over-sized sleeve, demostrates stenosis or angulation of the gastric tube, that could be the reason of the proximal gastric tube dilation and, records any inflammation, erosion or ulcer of the gastric and duodenal mucosa. Testing the Helicobacter pylori presence by antral mucosa biopsy is a routine attitude.

CT-scan with $3 \mathrm{D}$ reconstruction was the best tool to evaluate the volume of the gastric tube, the gastric tube was distended with effervescent sodium bicarbonate given orally, the helical CT images were acquired and reconstructed, the gastric volume was estimated with the software of the CT device. CT-scan also demostrates the shape and anatomic details of the gastric tube, may identify the stapled line of the gastric sleeve and its' mediastinal migration (Fig. 4). Ct-scan can also assess the enlargement of the diaphragmatic hiatus and the hiatal hernia if present (Fig. 5).

The 24-hour $\mathrm{pH}$ monitoring with impedance helped assessing the presence and the severity

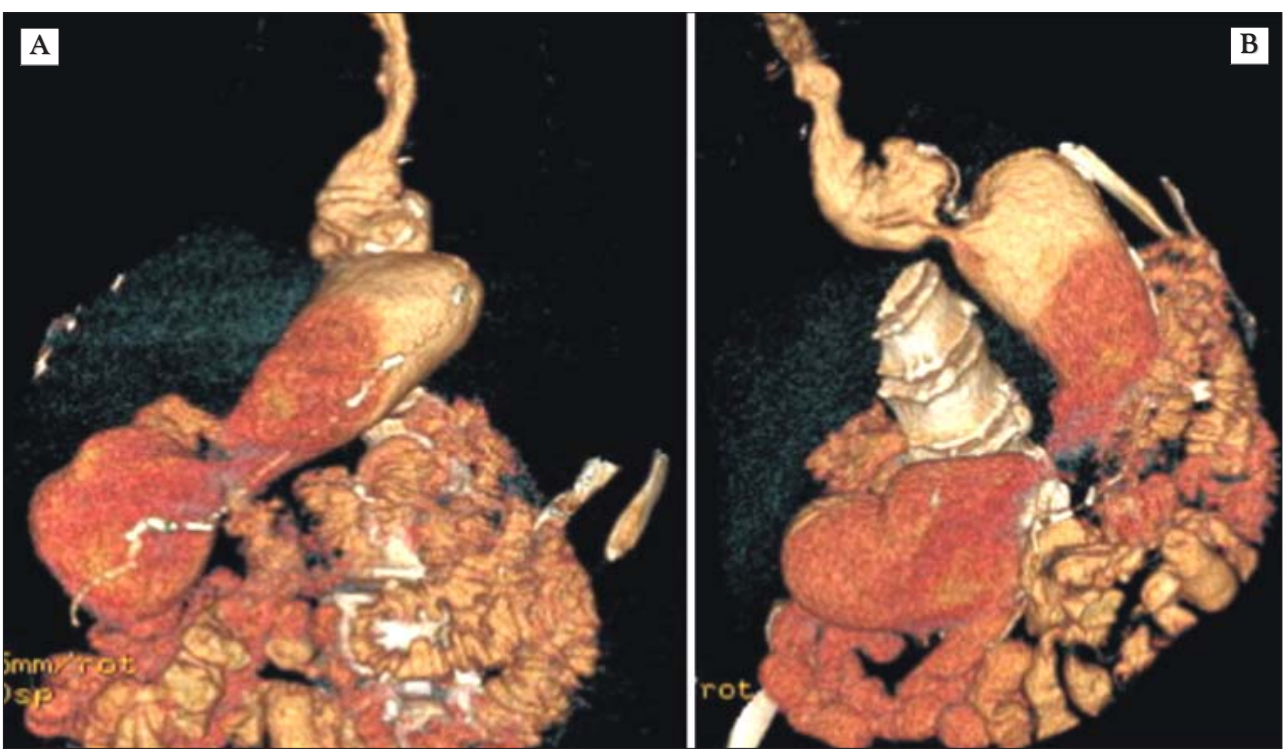

Figure 4. CT-scan with $3 \mathrm{D}$ reconstruction after LSG. (A) dilation of the gastric tube, dilated antrum after gastric sleeve; (B) the staple line can be well identified and followed above the diaphragm because of the intrathoracic migration of the gastric tube

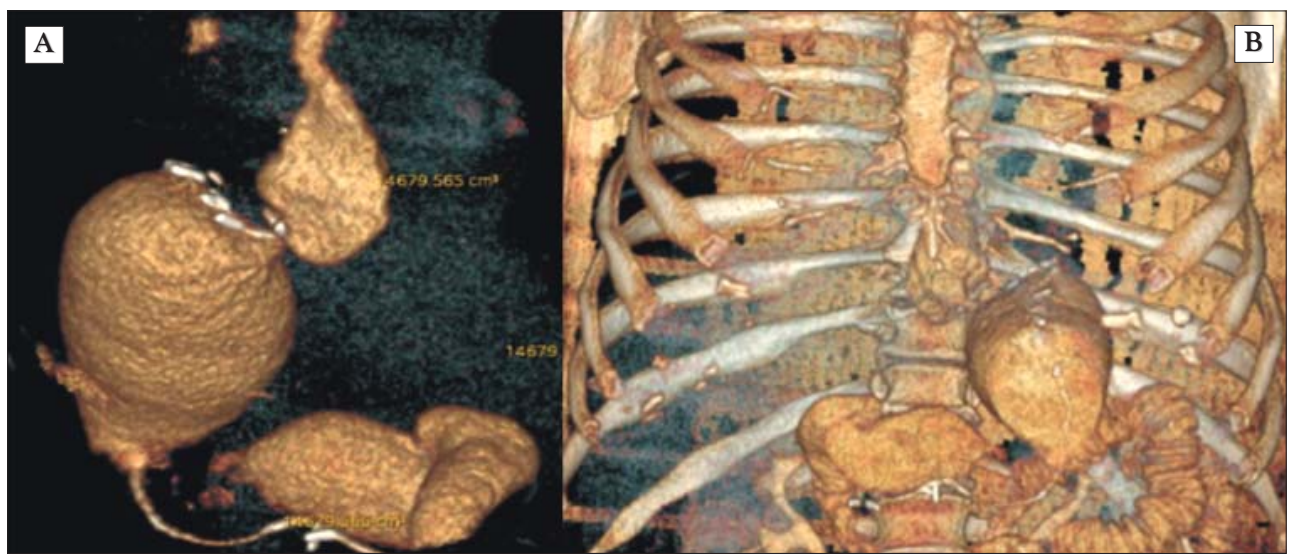

Figure 5. CT-scan with $3 D$ reconstruction after $L S G-(A)$ important dilation of the gastric fundus after gastric sleeve and hiatal hernia. (B) same patient, front view 
of GERD. By using DeMeester score, greater than 14.72 abnormal, 14.72-50 mild GERD, 50-100 moderate GERD, and greater than 100 severe GERD, we could better select the proper revisional options.

By correlating information from EGD, barium swallow, CT scan and 24-hours $\mathrm{pH}$ monitoring we consider the best revisional surgery option for each specific patient with regaining weight after LSG.

Conservative therapy was considered the initial treatment option in all these patients.

The decision for the type of revisional surgery depended on the gastric tube volume and function, but it was considering all the available medical information.

- For patients with increased volume of the gastric tube (over 250cc) demonstrated at barium swallow and confirmed at CT scan with $3 \mathrm{D}$ reconstruction, re-sleeve gastrectomy was proposed as revisional surgery.

- If the gastric volume measured below $200 \mathrm{cc}$, the patients were considered not eligible for Re-LSG and RYGBP or SADI was considered.

- The patients having intense GERD, severe esophagitis and high De-Meester scores were exclusively receiving RYGBP.

- The patients with a vicious geometry twisted, angulated - as cause for GERD were not receiving Re-LSG but RYGBP or another surgical procedure aiming to correct the complication.

\section{Surgical Technique}

The surgical technique for laparoscopic resleeve had been applied following the same surgical protocol consisting of five important steps (Fig. 6 A, B).

\section{Gastric Tube Dissection}

The $\mathrm{CO} 2$ pneumoperitoneum is induced by a Veress needle introduced in the left flank and, six ports of 5-12 mm are used for the laparoscopic Re-SLG. By carefully performing adhesiolysis, a proper exposure of the gastric tube is obtained (Fig. 7). Further dissection of the gastric antrum, of the posterior fundus and of the pre-cardial fat pad are often necessary. Moreover, the identification of the former stapled line on its complete aspect is mandatory. The gastric tube is inflated with
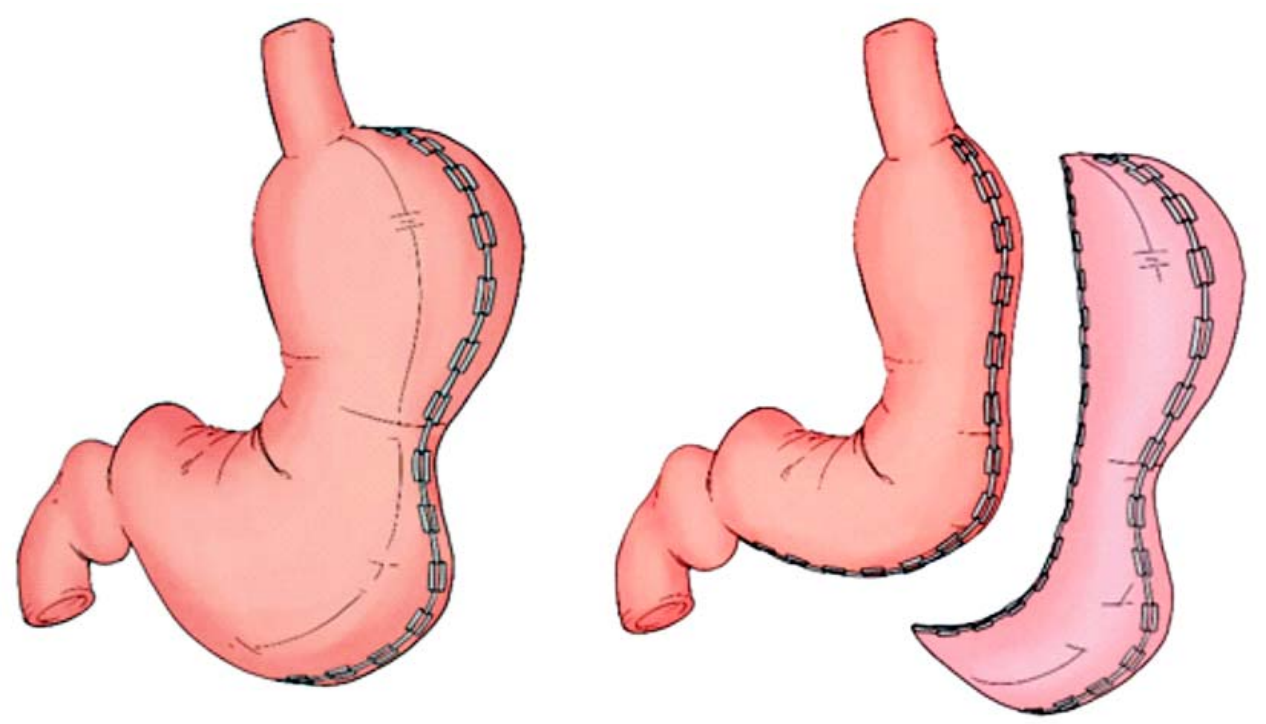

Figure 6. Schematic representation of the Re-LSG. (A) Dilated gastric tube after LSG; (B) Fashioning of the new $S G$, by reducing the excessive size of the former gastric tube 


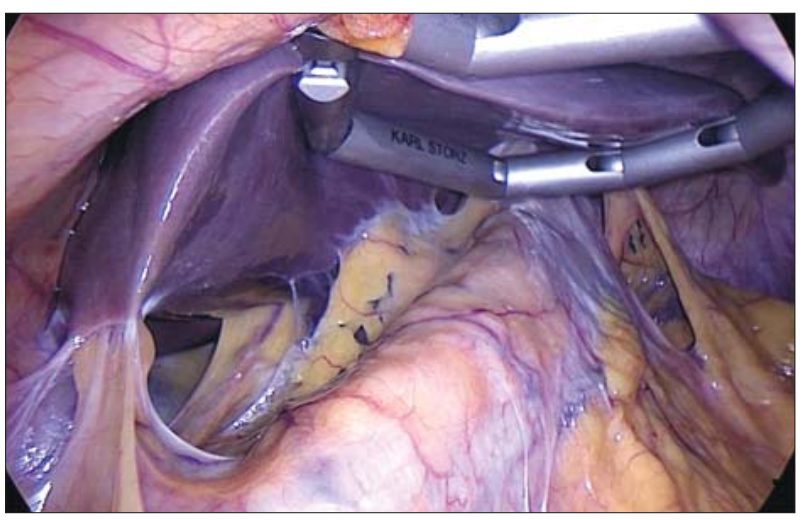

Figure 7. Re-LSG. Intraoperative image - few peritoneal adhesions are usually found after primary LSG

gas via a naso-gastric tube. Thus the actual dimensions of the stomach can be appreciated and the landmarks for the re-sleeve can be identified (Fig. 8 A, B).

\section{Hiatal Hernia Evaluation}

The active search for hiatal hernia (HH) is our standard protocol for revisional bariatric surgery. The $\mathrm{HH}$ is often demonstrated by the preoperative investigations and intraoperatively confirmed or discovered during the dissection. If there is an evidence of $\mathrm{HH}$, the circumferential dissection of the inferior esophagus aiming the cardia replacing $4 \mathrm{~cm}$ below the diaphragm, the crura approximation with 3-4 non-resorbable stiches posterior from esophagus are performed to complete the hiatal hernia repair (HHR) (Fig. 9). 2-3 stitches are used to fixate the esophagus in the intraabdominal position aiming to recreate the phreno-esophageal membrane.

\section{Re-Sleeve the Gastric Tube}

Longitudinal gastrectomy begins $1 \mathrm{~cm}$ from the pylorus, is guided by a $35 \mathrm{Fr}$ calibration tube and, ends up lateral to the gastroesophageal junction, left siding $1 \mathrm{~cm}$ the Hiss angle. The chosen height of the staplers is adapted to the thickness of the gastric wall, usually going for black cartridges. The previous stapled line should be always left outside of the actual gastric trimming line, to prevent any
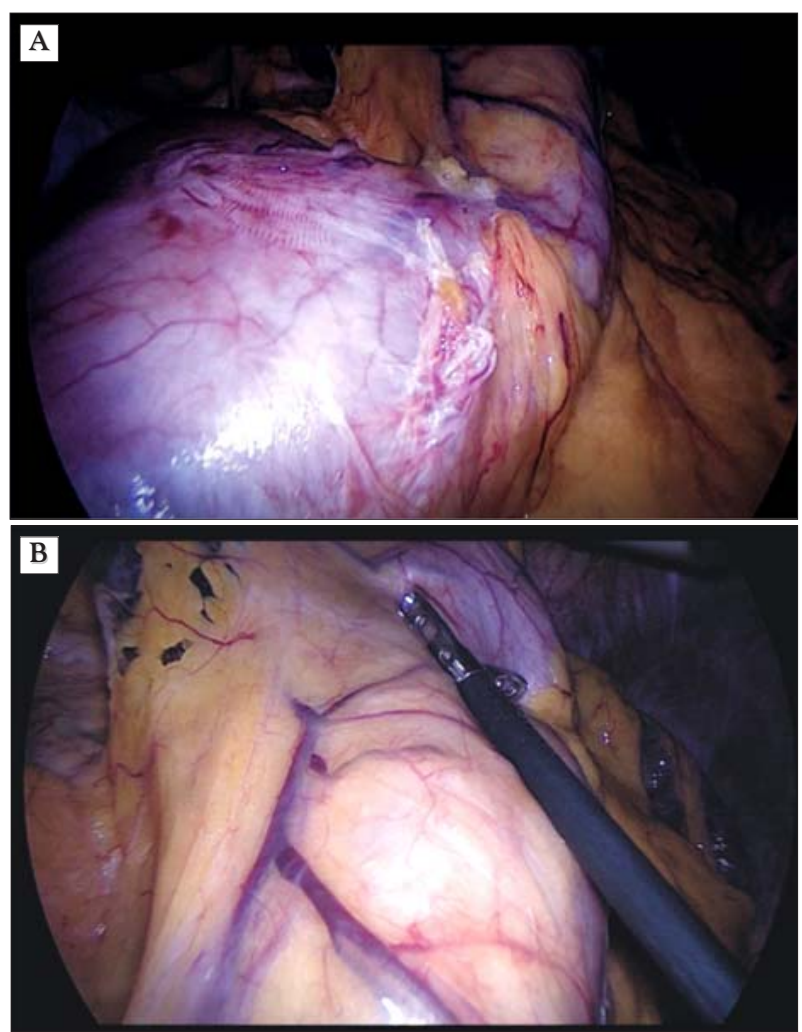

Figure 8. Re-LSG - Evaluation after adhesiolysis. (A) the stomach isdilated, and this is revealedby gastric gas insufflation. The antrum is undissected in this case. (B) the dimensions are measured with scaled graspers and the former staple line, in this case the gastric tube was dilated (right), and the antrum large and undissected (left)

ischemic area on the new stomach (Fig. $6 \mathrm{~B}$, Fig. 10). The stapled line is reinforced with 2.0 monofilament polypropylene running suture

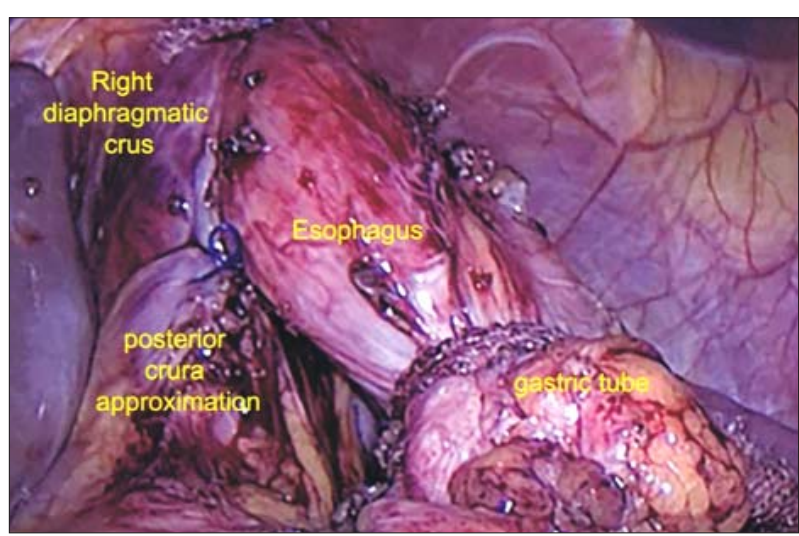

Figure 9. Re-LSG. Crura approximation with 3non-resorbable stiches posterior to esophagus is performed for the hiatal hernia repair (HHR) 


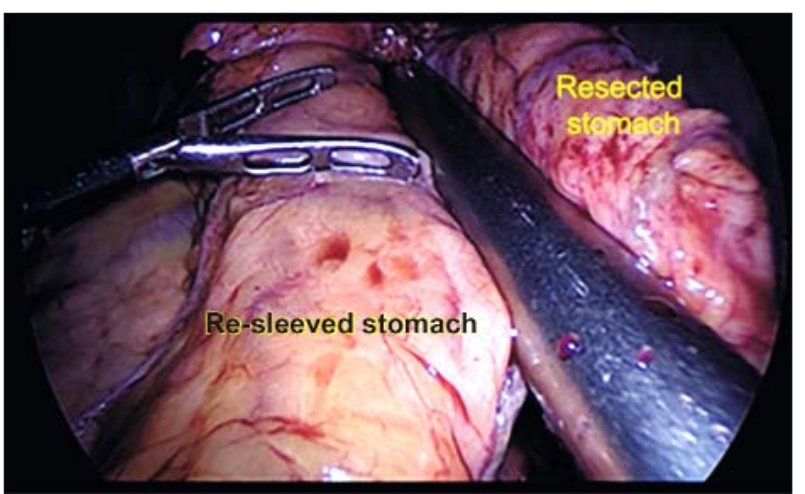

Figure 10. The chosen size of the staplers is adapted to the thickness of the gastric wall. The previous stapled line is left on the resected part of the stomach, to the right of the stapler in the picture.

and a18Fr nasogastric tube is left in place for 24 hours.

\section{Narbona-Arnau Cardiopexy}

If hiatal hernia was present and repaired, a Narbona-Arnau cardiopexy is considered. The condition of harvesting an intact teres ligamentum is mandatory for the success of the procedure. The wrapping of the ligament around the esogastric junction is secured with 3.0 nonresorbable stitches (19) (Fig. 11).

\section{Final Evaluation}

Adequate hemostasis is carefully evaluated after elevating the patient's blood pressure with $30 \%$ over its preoperative level. The methylene blue test is not only demonstrating the absence of any leak at the stapled line but the geometry of the new gastric tube. A $24 \mathrm{Fr}$ drainage tube is left in place near the stomach for 24 hours.

\section{Postoperative Management and Follow-up}

The patient starts oral intake on the first postoperative day and, if the liquids are well tolerated, the nasogastric tube is extracted. An upper GI radiologic study using Gastrografin swallow and an abdominal ultrasound examination are performed to all the patients, 48 hours after Re-LSG. The discharge is planned
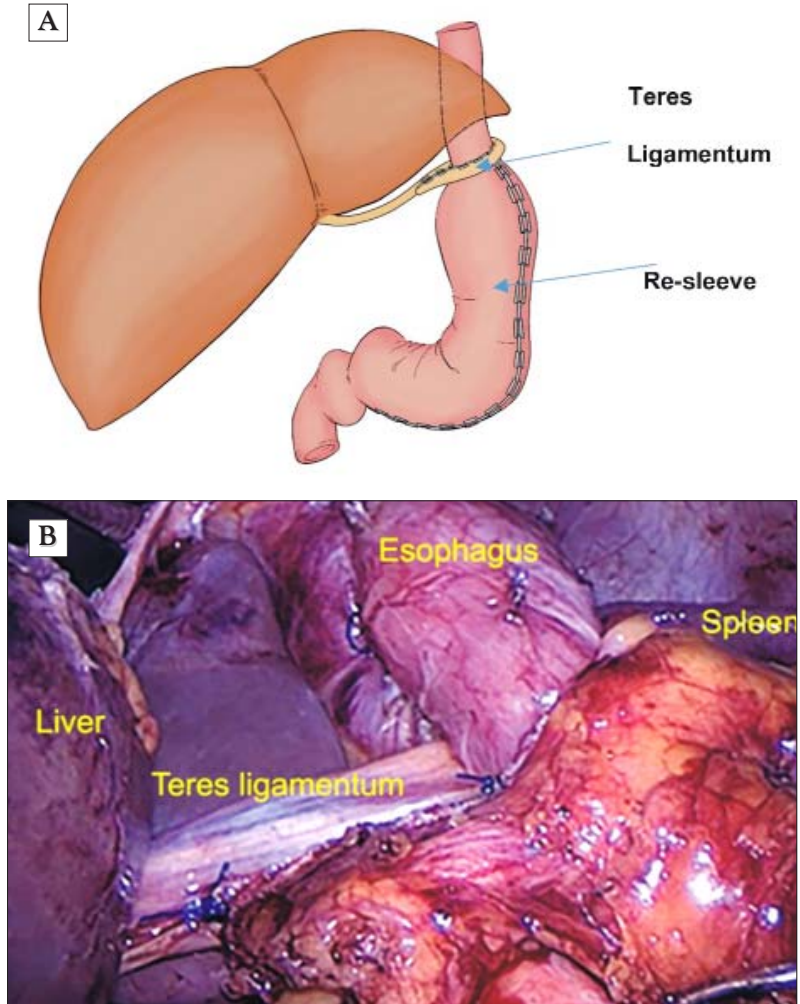

Figure 11. Narbona-Arnau cardiopexy and Re-LSG.

(A) schematic representation of Narbona-Arnau cardiopexy associated to Re-LSG; (B) Intraoperative aspect. Teres ligamentum is surrounding the esogastric junction

on the POD3 if, adequate liquid intake is demonstrated.

The postoperative nutritional regimen is like the primary LSG and it consists of clear liquid in the first week, followed by soft diet for the next 2 weeks, with gradual increases in food texture thereafter.

The follow-up visits are scheduled at 10 days, 1 month, 3 months, 6 months and 12 months after the surgery for the first postoperative year and then, every year after, to monitor the weight loss, the comorbidities' status, and the presence of any complications. Radiological studies are planned at 1,3,6,12 months after surgery while endoscopy on every year postoperative (Fig. 12).

Inadequate weight control was defined as percent of excess weight loss (\%EWL) less than $50 \%$ or BMI over $35 \mathrm{~kg} / \mathrm{m} 2$ at one year or more after the surgery. 


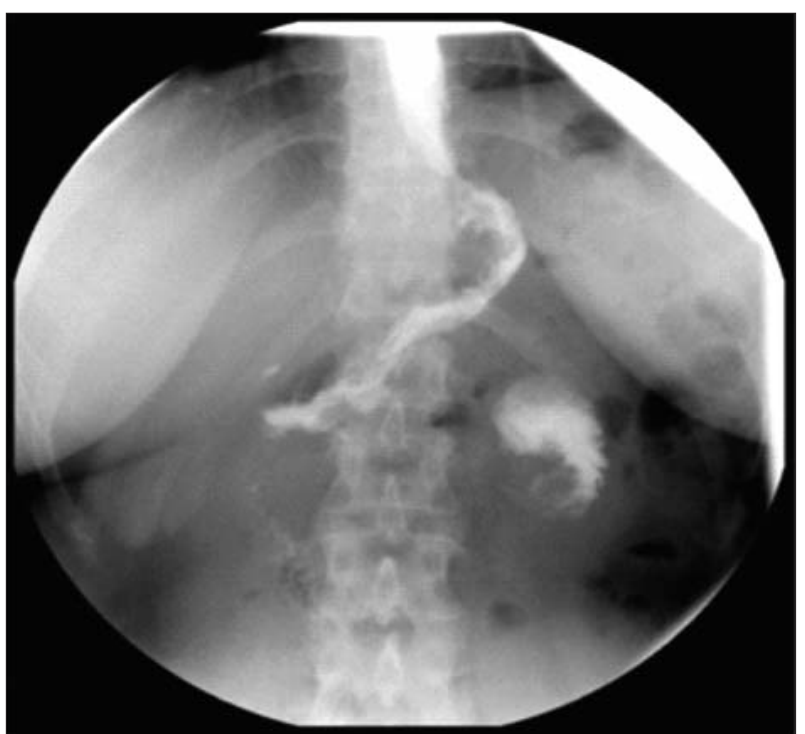

Figure 12. Barium swallow Study 1 month control after resleeve and hiatal hernia repair. To be observed the tight gastric tube, with good gastric emptying, no gastroesophageal reflux, uniform caliber, no stenosis, no twisting of the gastric tube. The intraabdominal presence of the inferior esophagus is checked. No signs of migration or hiatal hernia recurrence are demonstrated

\section{Statistical Analysis}

Statistical analysis was conducted with $\mathrm{R}$, version 3.5.3 (2019-03-11) Copyright (C) 2019 The R Foundation for Statistical Computing, $\mathrm{R}$ Core Team (2019). R: A language and environment for statistical computing. $\mathrm{R}$ Foundation for Statistical Computing, Vienna, Austria. URL https://www.R-project.org.

Data is presented as Mean \pm Standard Deviation (S.D) for continuous variables, and as absolute frequency / relative frequency for categorical variables.

To investigate if there are statistically significant differences between BMI at the four moments of measurement, we conduct a one-way, repeated measures ANOVA (ANOVA-RM), with dependent variable BMI and independent variable the moment of measurement (before re-sleeve, six months after re-sleeve, one year after re-sleeve, three years after re-sleeve). The result is statistically significant at $p<0.01$ and the $p$ value obtained is $\mathrm{p}<0.0001$, therefore there are at least two moments of measurement when BMI values are different.

In order to identify the sources of differences, we conduct a post-hoc procedure with paired $\mathrm{T}$ test, adjusted for multiple comparisons with Bonferroni correction.

A p-value less than 0.05 was considered for statistical significance.

\section{Results}

Twenty-seven patients were included in the study, identified to receive Re-SLG for weight regain in the analyzed period and succeeded to be evaluated at 6 months, 1 year and 3 years after the surgery.

Of the 27 patients $21(78 \%)$ were females and 6 males (22\%) and the mean age was 42 years (range $22-65$ years).

The mean BMI before Re-SLG was 35,69 $\mathrm{kg} / \mathrm{m}^{2}$ (range 28, 58-52). Six patients $(22 \%)$ had persistent comorbidities after the initial gastric sleeve such as hypertension, type II diabetes, dyslipidemia and sleep apnea.

The upper GI Study using barium swallow showed gastric dilation in all the patients and the gastric volume measured by $3 \mathrm{D}$ reconstruction CT- scan was over $250 \mathrm{cc}$. mean $395 \mathrm{cc}$ (range 280-570cc)

Of the 24 patients having HHR, nineteen (79\%) were preoperatively identified with $\mathrm{HH}$ at barium swallow study, upper digestive endoscopy and CT-scan while 5 cases (21\%) were intraoperatively discovered.

The time interval from initial sleeve to the Re-SLG was 5,14 years (range 6 months-11 years).

All the patients underwent Re-SLG by laparoscopic approach without any conversion to open surgery and no intraoperative complications. The mean operative time was $157 \mathrm{~min}$ (range 60-390 minutes). Twenty-four patients (88\%) had concurrent surgical procedures while seven of them had at least two associated procedures (Table 1).

Out of 24 patients with hiatal hernia repair nine underwent cruroraphy and NarbonaArnau cardiopexy and 15 underwent only cruroraphy. 
Table 1. Concurrent surgical procedures to re-sleeve in 24 out of 27 patients

\begin{tabular}{lc}
\hline Surgical procedure & No of the patients \\
\hline hiatal hernia repair & 24 \\
\hline Narbona-Arnau Cardiopexy & 9 \\
\hline cholecystectomy & 5 \\
\hline adnexectomy & 1 \\
\hline hysterectomy & 1 \\
\hline adrenalectomy & 1 \\
\hline
\end{tabular}

Mean hospital stay was 4 days (range 2-11 days).

We encountered one postoperative obstruction complication. The patient developed progressive dysphagia and gastric tube stenosis, diagnosed at 1 month after surgery and solved by three endoscopic dilation sessions, following an already published protocol (20).

We did not encounter any recurrence of hiatal hernia in the 24 patients with hiatal hernia repair at 3 years, either they received Narbona-Arnau procedure or only cruroraphy. Also no hiatal hernia was identified in the 3 patients who did not have HHR by the time of re-sleeve.

At 3 year follow-up two patients (7\%), one patient with re-sleeve and one patient with resleeve and HHR, were symptomatic for GERD and were on proton pump inhibitors PPI, both of them presenting grade $\mathrm{A}$ esophagitis at upper digestive endoscopy with no signs of hiatal hernia, by both upper digestive endoscopy and barium swallow.

No signs of GERD, clinically and by investigations such as barium swallow and EGD were found in the 9 patients with hiatal hernia repair by crururaphy and NarbonaArnau cardiopexy

No mortality was encountered.

No patient was lost for follow-up, but telephone interviews were used in five patients (19\%) for the 3 year postoperative evaluation.

The demographic data, perioperative data, results after re-sleeve in terms of BMI, EWL\% and comorbidities outcome at 6 months, 1 year and 3 years after Re-LSG are summarized in Table 2.

The differences between BMI at the four moments of measurement were investigated and the result is statistically significant at $\mathrm{p}<$ 0.01 , therefore there are at least two moments of measurement when BMI values are different.

We found out that the differences between initial BMI (before re-sleeve) and BMI for any other moments of measurement, 6 months, 1 year, 3 years postoperative are statistically significant $(\mathrm{p}<0.01)$.

Table 2. Summary of the data of the patients, perioperative data and results after re-sleeve

\begin{tabular}{lc}
\hline Variable & Patients Group (N = 27) \\
\hline Age - Mean \pm S.D & $42.51 \pm 11.52$ \\
Sex & $6(22.22)$ \\
M - Nr (\%) & $21(77.78)$ \\
F - Nr (\%) & $35.69 \pm 7.01$ \\
\hline BMl before re-sleeve - Mean \pm S.D & $28.39 \pm 5.32$ \\
\hline BMI Six Months after re-sleeve- Mean \pm S.D & $27.23 \pm 5.23$ \\
BMI One Year after re-sleeve - Mean \pm S.D & $27.65 \pm 5.13$ \\
\hline BMI Three Years after re-sleeve - Mean \pm S.D & $157.77 \pm 74.69$ \\
\hline Operative Time (min) - Mean \pm S.D & $4.07 \pm 1.76$ \\
\hline Hospital Stay (days) - Mean \pm S.D & $1(3.70)$ \\
\hline Postoperative complications & $26(96.30)$ \\
Yes - Nr (\%) & $5.14 \pm 2.24$ \\
No - Nr (\%)
\end{tabular}

(Data is presented as Mean \pm Standard Deviation (S.D) for continuous variables, and as absolute frequency / relative frequency for categorical variables) 
In contrast the differences between BMI at 6 months and BMI at 1 year, BMI at 6 months and BMI at 3 years, BMI at 1 year and BMI at 3 years are not statistically significant $(\mathrm{p}=0.9999)$

The mean EWL (\%) at 6 months, 1 year and 3 years (relative to the initial value of BMI) were: $83.88 \pm 43.72,94.45 \pm 45.35$ and $85.41 \pm$ 43.92 respectively. We notice very good results at 6 months, the maximum excess weight loss is at one year, while EWL is lower at three years than at that of one year.

The evolution in time of BMI and EWL at the specific moments of measurement can be followed in Graph 1 and Graph 2.

All the 6 patients who presented comorbidities before re-sleeve had remission of their diseases at one year postoperative. The recurrence of hypertension and dyslipidemia was noticed in one patient, 3 years after re-SLG. This patient had BMI $=35 \mathrm{~kg} / \mathrm{m}^{2}$ at 3 years postoperative, BMI $=42 \mathrm{~kg} / \mathrm{m}^{2}$ before re-sleeve, and a minimal BMI of $34,05 \mathrm{~kg} / \mathrm{m}^{2}$ one year after re-sleeve.

\section{Discussions}

As the obesity is a global health problem and the number of bariatric procedures is rising more revisional cases are expected. Aside from the reoperations aiming to manage early or late postoperative complications, many bariatric patients may require another surgical procedure for insufficient weight loss, weight regain or relapse of the metabolic complications. This category of procedures is named revisional bariatric surgery and it comprises $5 \%-15 \%$ of total cases of bariatric surgery (1-3). The rate of revisional surgery is $20 \%$ 60\% after LAGB (4-8), 9\%-17\% after RYGB (7, $9,10)$, and $9 \%-11 \%$ after SG $(11,12)$. Although many articles have investigated the results of various bariatric procedures used for morbid obesity, studies addressing the best revisional surgery of choice after various primary surgery remain limited.

Revisional bariatric surgery is complex and technically demanding. It is generally associated with a higher risk of postoperative complications than that of primary procedures, and the perioperative morbidity rate is reportedly $19 \%-50 \% \quad(3,21-23)$. With the advancement of laparoscopic surgical skills, several studies have recently demonstrated that laparoscopic revision can be performed safely by well-trained and highly experienced bariatric surgeons in specialized bariatric centers $(24,25)$.

In the past years gastric sleeve has become the preferred bariatric procedure and as the time after initial sleeve is passing, the number of revisions after LSG is expected to rise. The

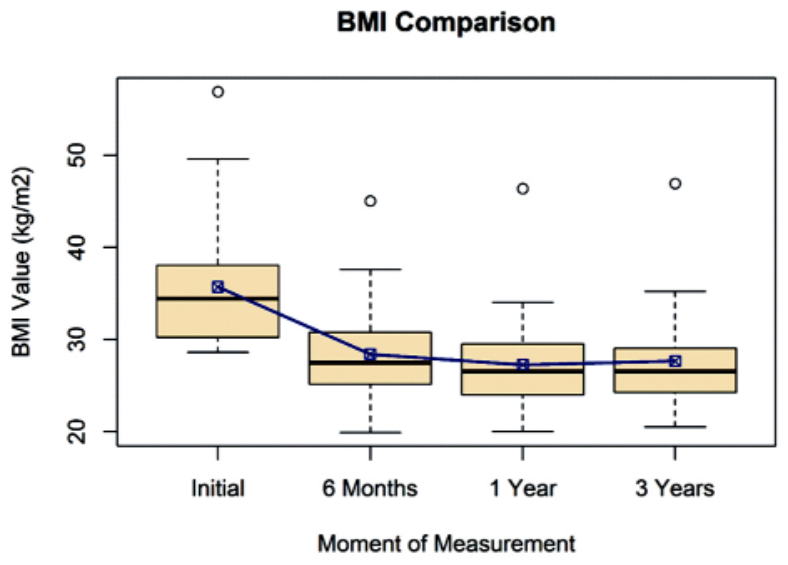

Graph 1. The graph shows BMI evolution in time, blue points on boxplots are means of BMI values at the moment of measurement

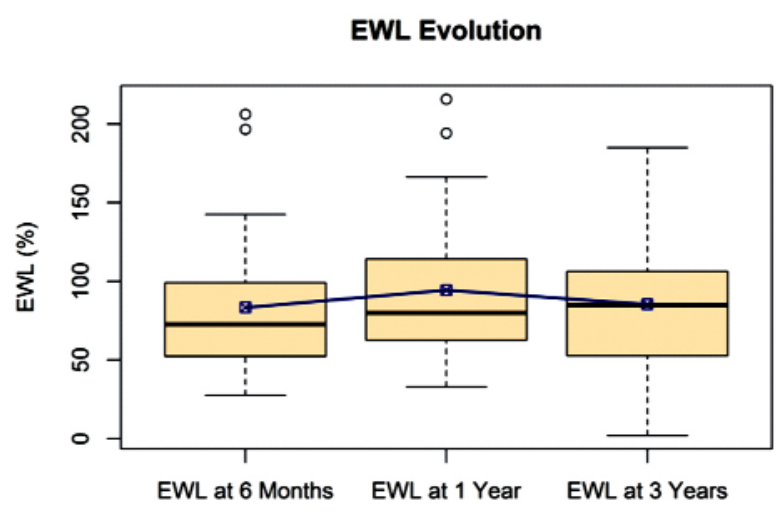

Graph 2. The graph shows EWL evolution in time, blue points on boxplots are means of EWL values at the moment of measurement 
LSG patients can experience a progressive weight regain after an inadequate weight loss after LSG (defined as loss of less than $50 \%$ of excess weight) or after reaching the optimal weight loss (1).

The decision to select the proper revisional bariatric surgery procedure is considered after performing an extended evaluation of the patient's alimentary behavior and medical status, and of the anatomy of LSG. The selection is considering re-sleeve (Re-SLG), banding the sleeve (B-SG), Roux en Y gastric bypass RYGB/ one anastomosis gastric bypass (OAGB), duodenal switch (DS) or single anastomosis duodeno-ileal bypass (SADI) (3, $6,13,15-17)$. Re-LSG is considered in patients with dilated gastric tube, entirely or at the antral part, with a large gastric fundus, having in common a too large capacity of the stomach (9-11).

Re-sleeve may have some advantages comparing with the other malabsorptive procedures by increasing restriction, lowering gastric output, less complications, like dumping syndrome or consequences of malabsorptionprotein deficit, hypovitaminosis, anemia and, by achieving a better quality of life.

We have introduced Re-LSG to control the weight regain after an initial LSG in 2008 and good results were encountered. A decisionmaking algorithm and a surgical protocol to manage the patients nonresponding to a former LSG was developed in the meantime in our institution.

The objective of this study was to evaluate the efficiency of laparoscopic re-sleeve as a revisional procedure for patients presenting weight regain after LSG, in a Bariatric Surgery Center of Excellence.

Re-sleeve is indicated as revisional surgery procedure for cases with gastric tube dilation. Mean gastric volume is increasing in time after gastric sleeve, even in tight sleeves $(26,27)$.

The dilation of the gastric tube after initial gastric sleeve is considered primary dilation, if at the initial gastric sleeve, the antrum or fundus were not resected or the initial calibration was too large, or secondary dilation if, after the former gastric sleeve, the tube was correctly calibrated but, suffered, in time, a global dilation (28-30).

Re-SG can be considered when gastric volumetry study reveals a remnant gastric volume more than $250 \mathrm{ml}$, in case of initially performed tight sleeve (i.e. dilatation after the initial SG) and/or when a large gastric fundus and/or antrum is present (i.e. technical failure of the initial SG) (28-30).

For a proper evaluation of the gastric dilation after the initial sleeve we preferred to do barium swallow study and CT-scan volumetric evaluation, although, other authors, completed barium swallow with CT-scan only for cases with inconclusive or negative dilation at barium swallow $(28,31)$.

In our re-sleeve studied group, the mean BMI before re-sleeve was $35.69 \mathrm{~kg} / \mathrm{m}^{2}$, close to most data in literature mean BMI $38.1 \mathrm{~kg} / \mathrm{m}^{2}$ (28), $38.9 \mathrm{~kg} / \mathrm{m}^{2}$ (32), $38.9 \mathrm{~kg} / \mathrm{m}^{2}$ (33), 39.9 $\mathrm{kg} / \mathrm{m}^{2}$ (29), $44.6 \mathrm{~kg} / \mathrm{m}^{2}$ (34) $46,1 \mathrm{~kg} / \mathrm{m}^{2}$ (35) contrasting with the mean of BMI $53.1 \mathrm{~kg} / \mathrm{m}^{2}$ (36).

The mean operative time in our study was 157 min similar with other data $137.5 \mathrm{~min}$ (32) and higher comparing with other studies: $96 \min$ (36), $39 \min$ (28) $43 \mathrm{~min}$ (29) $55.8 \mathrm{~min}$ (33). This can be explained in our study by the frequent associated surgical procedures, in 24 out of 27 patients (88.89\%).

\section{Concurrent surgery}

Hiatal hernia was the most frequent associated procedure, in $88.89 \%$ of cases in our study. This is predictable because, hiatal hernia is frequently associated with obesity, and often missed or not repaired during the primary bariatric procedure. Moreover, after gastric sleeve, we may encounter many cases of gastric tube mediastinal migration, demonstrated at barium swallow or CT-scan studies. The used marker for the upper end of the gastric stapled line is a ML Titanium clip and its positioning can be often radiologically seen above the diaphragm. Despite the extensive preoperative work-up - upper gastrointestinal barium swallow, EGD and CT- scan with 3D reconstruction - we were able to preoperative 
diagnose HH only in 19 patients $(79.16 \%)$. For the rest of the 5 patients (20.84\%), HH was intraoperatively diagnosed, as a result of our protocol of intraoperative active search for hiatal hernia.

The extensive preoperative work-up, aiming the identification of hiatal hernia, the preoperative 24 hour $\mathrm{pH}$ monitoring which excluded the patients with severe GERD for Re-LSG, the intraoperative searching for hiatal hernia and its' repair, are the reasons for the low rate of GERD 3 years after ReLSG. Esophagitis Los Angeles A was found only in 2 patients out of 27 (7.4\%).

Cruroraphy associated with NarbonaArnau cardiopexy may offer an advantage to HHR alone in preventing GERD. Our results, at 3 years follow-up, are demonstrating no GERD in the nine 9 patients with NarbonaArnau cardiopexy, and one patient with GERD after re-sleeve and HHR by cruroraphy, out of 15 patients who underwent this procedure. Studies on higher number of patients could offer a stronger argument in choosing the best procedure for hiatal hernia repair in order to prevent GERD on long term follow-up after re-sleeve.

Hospital stay was mean 4 days, with 1 day longer than hospitalization after primary sleeve in our clinic and close to data in other studies mean 3.5 days (28), 5 days (33) and much shorter than other studies 11 days (32) despite the high number of simultaneous surgical procedures.

In our study, the time interval from the initial sleeve to the re-sleeve was a mean period of 5.14 years, much is longer than in other studies, 37 months (28), 37 months (32), 34.5 months (29).

We found in literature many studies publishing their results at 1 year after resleeve (16-19), when the good results are predictable, consecutive to the short-term weight loss and comorbidities remission after gastric sleeve.

Studies with a longer follow-up of 20 months (28,29), 23 months, (32) present their results on a mean period of time, that mix the results of weight loss and comorbidities outcome between different moments after re-sleeve. Thus, the outcomes of the first postoperative year, when the patient obtains the maximal weight loss and comorbidities remission, are combined with the results of the following postoperative years, when the patient is either maintaining the result, continues to lose weight or, regains weight and may maintain or not the comorbidities' remission.

We preferred to analyze the results after re-sleeve at the standard intervals of 6 months, 1 year and 3 years after surgery, considering this more accurate than a mean time of follow up. All the patients were evaluated for their weight loss and comorbidities outcome at the same time interval after the revisional surgery (re-sleeve), with more relevant and conclusive results on a medium-term follow-up.

Our results revealed very good outcomes after re-sleeve, as the patients are losing most of their excess weight in the first 6 months, almost all excess in 1 year after surgery and were able to maintain their results at 3 years after re-sleeve, with a slight increase at three years of the mean BMI comparing with BMI at 1 year but, maintaining a mean BMI at three years lower than at 6 months and a slight reduction of mean EWL at 3 years comparing with 1 year. The differences are statistically significant between initial BMI before re-sleeve and the BMI for all other moments of measurement -6 months, 1 year, 3 years (Table 3 ).

Data in literature presents similar results in terms of BMI, at shorter period of follow up, with the mean BMI of $27.3 \pm 5.2 \mathrm{~kg} / \mathrm{m}^{2}$, mean $\%$ EWL $100 \% \pm 21.1 \mathrm{~kg}$ at mean 23 months follow-up (32), mean BMI $29.2 \mathrm{~kg} / \mathrm{m}^{2}$ (28) and mean\% EWL 58,5\% $( \pm 25.3)$ for mean 20 months follow-up (29), mean BMI $27.5 \mathrm{~kg} / \mathrm{m}^{2}$, mean \%EWL $71.4 \%$ at 12 months follow-up (18), mean BMI $32.5 \mathrm{~kg} / \mathrm{m}^{2}$ and mean \%EWL $56.8 \%$ at 1 year follow-up (33); mean BMI 36.5 $\mathrm{kg} / \mathrm{m}^{2}$ with mean $\% \mathrm{EWL} 60 \%$ at 12 months (36).

We appreciate our medium-term results at 3 years after re-sleeve as very good with the 
Table 3. The differences between initial BMI (before re-sleeve) and BMI for any other moments of measurement, 6 months, 1 year, 3 years postoperative are statistically significant $(p<0,01)$

\begin{tabular}{lc}
\hline Contrasts & P Value \\
Intial BMI compared toBMI at Six Months & $<0.0001$ \\
Initial BMI compared to BMl at One Year & $<0.0001$ \\
\hline Initial BMI compared to BMl at Three Years & $<0.0001$ \\
\hdashline BMl at Six Months compared to BMI at One Year & 0.9999 \\
BMl at Six Months compared to BMl at Three Years & 0.9999 \\
BMI at One Years compared to BMI at Three Years & 0.9999 \\
\hline
\end{tabular}

mean BMI of $27.65 \pm 5.13 \mathrm{~kg} / \mathrm{m}^{2}$ and the mean $\% \mathrm{EWL}$ of $85.41 \pm 43.92$. Moreover, to our best knowledge, this study presents the longest follow up data after re-sleeve published so far.

Comorbidities are ameliorated and remitted after re-sleeve, as shown in our study. The 6 patients who presented comorbidities before resleeve had complete remission of their diseases after the first postoperative year. One patient was recorded with recurrence of hypertension and dyslipidemia at 3 years postoperative. This results match with those published in literature $(33,36)$.

Dapri et al. compared laparoscopic resleeve versus duodenal switch after sleeve gastrectomy and the results showed a better efficacy of duodenal switch versus re-sleeve because of complications easier to manage after duodenal switch than re-sleeve, the risk of fistula development after re-sleeve is difficult to treat, is the opinion of the authors, but the study is on a small number of patients - 7 patients underwent re-sleeve, one with leak (32). However, in our study on 27 patients there was no fistula or leakage encountered, other studies also do not report any fistula after re-sleeve $(28,33,36)$.

Long-term studies investigating the results after re-sleeve and other revisional procedures, as well comparative studies between different revisional procedures are awaited. They may confirm our good results and should help bariatric surgeons to choose the right revisional procedure for their patient.

Our study has certain limitation due to its retrospective design and the small sample size. However, is analyzing mid-term outcomes after sleeve in a single center, designated as BS-CoE.

\section{Conclusions}

- Our study demonstrate that laparoscopic re-sleeve gastrectomy is an efficient revisional bariatric procedure succeeding to correct weight regain and comorbidities relapse after the initial sleeve, with very good results on medium term follow-up.

- Studies investigating the results on longterm after gastric re-sleeve are awaited. Further prospective clinical trials are required to compare the outcomes of redo-sleeve to other revisional procedures addressed to weight regain after LSG: laparoscopic Roux-en-Y gastric bypass or duodenal switch.

\section{Conflict of Interest}

The authors declared no conflict of interest.

\section{Acknowledgement}

The drawings are performed by Filip Mihnea Copaescu.

\section{References}

1. Radtka JF, 3rd, Puleo FJ, Wang L, Cooney RN. Revisional bariatric surgery: who, what, where, and when? Surg Obes Relat Dis. 2010;6(6):635-42.

2. Behrns KE, Smith CD, Kelly KA, Sarr MG. Reoperative bariatric surgery. Lessons learned to improve patient selection and results. Ann Surg. 1993;218(5):646-53.

3. Spyropoulos C, Kehagias I, Panagiotopoulos S, Mead N, Kalfarentzos F. Revisional bariatric surgery: 13-year experience from a tertiary institution. Arch Surg. 2010;145(2):173-7.

4. Boza C, Gamboa C, Perez G, Crovari F, Escalona A, Pimentel F, et al. Laparoscopic adjustable gastric banding (LAGB): surgical results and 5-year follow-up. Surg Endosc. 2011;25(1):292-7.

5. Himpens J, Cadiere GB, Bazi M, Vouche M, Cadiere B, Dapri G. Long-term outcomes of laparoscopic adjustable gastric banding. 
Arch Surg. 2011;146(7):802-7.

6. O'Brien PE, MacDonald L, Anderson M, Brennan L, Brown WA. Long-term outcomes after bariatric surgery: fifteen-year follow-up of adjustable gastric banding and a systematic review of the bariatric surgical literature. Ann Surg. 2013;257(1):87-94.

7. Romy S, Donadini A, Giusti V, Suter M. Roux-en-Y gastric bypass vs gastric banding for morbid obesity: a case-matched study of 442 patients. Arch Surg. 2012:147(5):460-6.

8. Van Nieuwenhove $\mathrm{Y}$, Ceelen W, Stockman A, Vanommeslaeghe $\mathrm{H}$, Snoeck E, Van Renterghem K, et al. Long-term results of a prospective study on laparoscopic adjustable gastric banding for morbid obesity. Obes Surg. 2011;21(5):582-7.

9. Higa K, Ho T, Tercero F, Yunus T, Boone KB. Laparoscopic Roux-enY gastric bypass: 10-year follow-up. Surg Obes Relat Dis. 2011; 7(4):516-25.

10. Himpens J, Coromina L, Verbrugghe A, Cadiere GB. Outcomes of revisional procedures for insufficient weight loss or weight regain after RouX-en-Y gastric bypass. Obes Surg. 2012;22(11):1746-54.

11. van Rutte PW, Smulders JF, de Zoete JP, Nienhuijs SW. Indications and short-term outcomes of revisional surgery after failed or complicated sleeve gastrectomy. Obes Surg. 2012;22(12):1903-8.

12. Weiner RA, Theodoridou S, Weiner S. Failure of laparoscopic sleeve gastrectomy--further procedure? Obes Facts. 2011;4 Suppl 1:42-6.

13. Himpens J, Dobbeleir J, Peeters G. Long-term results of laparoscopic sleeve gastrectomy for obesity. Ann Surg. 2010;252(2):31924.

14. Regan JP, Inabnet WB, Gagner M, Pomp A. Early experience with two-stage laparoscopic Roux-en-Y gastric bypass as an alternative in the super-super obese patient. Obes Surg. 2003;13(6):861-4.

15. Karcz WK, Marjanovic G, Grueneberger J, Baumann T, Bukhari W, Krawczykowski D, et al. Banded sleeve gastrectomy using the GaBP ring--surgical technique. Obesity facts. 2011;4(1):77-80.

16. Lemmens L, Van Den Bossche J, Zaveri H, Surve A. Banded Sleeve Gastrectomy: Better Long-Term Results? A Long-Term Cohort Study Until 5 Years Follow-Up in Obese and Superobese Patients. Obesity surgery. 2018;28(9):2687-95.

17. Tognoni V, Benavoli D, Bianciardi E, Perrone F, Ippoliti S, Gaspari A, et al. Laparoscopic Sleeve Gastrectomy versus Laparoscopic Banded Sleeve Gastrectomy: First Prospective Pilot Randomized Study. Gastroenterol Res Pract. 2016;2016:6419603-.

18. Sami SS, Ragunath K. The Los Angeles Classification of Gastroesophageal Reflux Disease. Video Journal and Encyclopedia of GI Endoscopy. 2013;1(1):103-4.

19. C.Copaescu. Cardiopexy with Teres Ligament - A Simple and Efficient Surgical Procedure to Control GERD in LSG. Obesity Surgery. 2015;25(1):1-364

20. Turcu F, Balahura C, Doras I, Constantin A, Copaescu C. Symptomatic Stenosis after Laparoscopic Sleeve Gastrectomy -
Incidence and Management in a High-Volume Bariatric Surgery Center. Chirurgia (Bucur). 2018;113(6):826-36.

21. Sugerman HJ, Kellum JM, Jr., DeMaria EJ, Reines HD. Conversion of failed or complicated vertical banded gastroplasty to gastric bypass in morbid obesity. Am J Surg. 1996;171(2):263-9.

22. Owens BM, Owens ML, Hill CW. Effect of Revisional Bariatric Surgery on Weight Loss and Frequency of Complications. Obes Surg. 1996:6(6):479-84.

23. Schwartz RW, Strodel WE, Simpson WS, Griffen WO, Jr. Gastric bypass revision: lessons learned from 920 cases. Surgery. 1988;104(4):806-12.

24. Victorzon M. Revisional bariatric surgery by conversion to gastric bypass or sleeve--good short-term outcomes at higher risks. Obes Surg. 2012;22(1):29-33.

25. Gagner M, Gentileschi P, de Csepel J, Kini S, Patterson E, Inabnet WB, et al. Laparoscopic reoperative bariatric surgery: experience from 27 consecutive patients. Obesity surgery. 2002;12(2):254-60.

26. Braghetto I, Cortes C, Herquinigo D, Csendes P, Rojas A, Mushle M, et al. Evaluation of the radiological gastric capacity and evolution of the BMI 2-3 years after sleeve gastrectomy. Obes Surg. 2009;19(9):1262-9.

27. Langer FB, Bohdjalian A, Felberbauer FX, Fleischmann E, Reza Hoda MA, Ludvik B, et al. Does gastric dilatation limit the success of sleeve gastrectomy as a sole operation for morbid obesity? Obes Surg. 2006;16(2):166-71.

28. Nedelcu M, Noel $P$, lannelli A, Gagner M. Revised sleeve gastrectomy (re-sleeve). Surg Obes Relat Dis. 2015;11(6):1282-8.

29. Noel P, Nedelcu M, Nocca D, Schneck AS, Gugenheim J, lannelli A, et al. Revised sleeve gastrectomy: another option for weight loss failure after sleeve gastrectomy. Surg Endosc. 2014;28(4):1096-102.

30. Silecchia G, De Angelis F, Rizzello M, Albanese A, Longo F, Foletto M. Residual fundus or neofundus after laparoscopic sleeve gastrectomy: is fundectomy safe and effective as revision surgery? Surg Endosc. 2015;29(10):2899-903.

31. Hany M IMI. Is Re-sleeve Gastrectomy after Sleeve Gastrectomy Failure Feasible? Egypt J Surg. 2018;37:5-8.

32. Dapri G, Cadiere GB, Himpens J. Laparoscopic repeat sleeve gastrectomy versus duodenal switch after isolated sleeve gastrectomy for obesity. Surg Obes Relat Dis. 2011;7(1):38-43.

33. Cesana G, Uccelli M, Ciccarese F, Carrieri D, Castello G, Olmi S. Laparoscopic re-sleeve gastrectomy as a treatment of weight regain after sleeve gastrectomy. World J Gastrointest Surg. 2014; 6(6):101-6.

34. Iannelli A, Schneck AS, Noel P, Ben Amor I, Krawczykowski D, Gugenheim J. Re-sleeve gastrectomy for failed laparoscopic sleeve gastrectomy: a feasibility study. Obes Surg. 2011;21(7):832-5.

35. Mehmet B. Re-Sleeve Gastrectomy for Failed Primary Laparoscopic Sleeve Gastrectomy. J Coll Physicians Surg Pak. 2019;29(1):62-5. 